\title{
Standard Gamble to Derive Utility Health States for Limbal Stem Cell Deficiency
}

This article was published in the following Dove Press journal:

ClinicoEconomics and Outcomes Research

\section{Adam B Smith \\ Jenny Retzler (D) Matthew J Taylor (D)}

York Health Economics Consortium Ltd, University of York, York YOIO 5NQ, UK
Correspondence: Adam B Smith

York Health Economics Consortium Ltd., Enterprise House, Innovation Way,

University of York, York YOI0 5NQ,

United Kingdom

Tel +44 1904363220

$\mathrm{Fax}+441904323628$

Email adam.smith@york.ac.uk
Purpose: To generate UK health-related quality-of-life (HRQoL) data for adult patients with moderate-to-severe limbal stem cell deficiency (LSCD), unilateral or bilateral, due to physical or chemical ocular burns to help inform economic evaluations of treatments.

Patients and Methods: EQ-5D-3L with vision bolt-on scores was prospectively measured for one of five clinical scenarios of LSCD described in vignettes in a demographically representative population of $520 \mathrm{UK}$ adults. These were converted to health state utilities using three different UK value sets. A standard gamble (SG) was then undertaken using 12 SG scenarios to examine the component drivers of health utility for the treatment of LSCD. Results: For the EQ-5D-3L scenarios, the mean disutility for LSCD with poor visual acuity, pain and disfigurement in both eyes compared to one eye was -0.084 (range $=-0.156$ to -0.045 across the value sets). The mean disutility of bilateral LSCD with pain, disfigurement, and poor visual acuity compared to unilateral LSCD with only poor visual acuity in one eye was -0.104 (range $=-0.151$ to -0.078 ). Similarly, where one eye was affected, pain and disfigurement in combination were associated with a greater mean disutility than improvements in visual acuity alone: -0.011 (range $=-0.04$ to 0.005 ). Mean SG utilities were within a narrow range $(0.682-0.765)$. Where one eye was affected, the main driver was disfigurement: mean utility was $0.731(0.709-0.753)$ compared to $0.682(0.659-0.704)$ when disfigurement was removed compared to vision restored to normal. For bilateral LSCD, mean utilities were $0.693(0.672-0.715)$ for normal vision and $0.75(0.73-0.771)$ when disfigurement and pain were removed.

Conclusion: Improvements in pain and disfigurement appeared to be the main factors driving differences in health utilities associated with symptom profiles in LSCD, with improvements in visual acuity having lesser impact.

Keywords: standard gamble, utility states, limbal stem cell deficiency, LSCD, ocular burns, holoclar $^{\circledR}$

\section{Introduction}

Limbal stem cell deficiency (LSCD) is a rare condition, most often caused by chemical or physical burn injuries to the eye, ${ }^{1}$ resulting in the loss of long-lived progenitor cells (limbal stem cells). These cells are required for the transparent layer at the front of the eye (corneal epithelium) to continuously regenerate throughout life and, importantly, to repair itself following injury. LSCD may affect one or both eyes and left untreated results in chronic pain, burning, photophobia, inflammation, corneal neovascularization (blood vessels growing over the front of the eye), scarring of the underlying eye structures and reduction or complete loss of vision. $^{2,3}$ Disfigurement of the eye often accompanies LSCD and can lead to serious 
psychological problems including depression and suicidality. ${ }^{4}$ In February 2015, Holoclar ${ }^{\circledR} 79,000-316,000$ cells $/ \mathrm{cm}^{2}$ living tissue equivalent (ex vivo expanded autologous human corneal epithelial cells containing stem cells), Chiesi Farmaceutici S.p.A., became the first advanced therapy medicinal product (ATMP) containing stem cells to receive a Marketing Authorisation in Europe and is currently indicated for the treatment of adult patients with moderate-to-severe LSCD, unilateral or bilateral, due to physical or chemical ocular burns ${ }^{5}$. Holoclar is the first medicine recommended for the treatment of $\operatorname{LSCD}^{5}$ and is also the first medicine in modern times to have been authorised entirely on the basis of retrospective data. ${ }^{6}$ Indeed, the recommendation to approve Holoclar is considered one of the most significant milestones achieved by the European Medicines Agency in the last 20 years. $^{7}$ However, the nature of these data also brings challenges for health outcomes research and subsequent policy decision-making. The studies of Holoclar were conducted in one country only (Italy), did not include any patientreported outcomes or measure of health utilities, included no control arm, and presented no possibility of acquiring valid health-related quality-of-life (HRQoL) data from treated patients, some of whom received treatment for up to 20 years ago. Therefore, in order to support health technology assessment (HTA) submissions to relevant authorities, quality-of-life data or health state utilities are required in order to capture the benefit of Holoclar ${ }^{\mathbb{B}}$ in the treatment of LSCD. Health states utilities may either be derived using preference-based instruments such as the EQ-5D and SF-6D, ${ }^{8,9}$ which have population-based algorithms to convert raw scores into preference-based health utilities. Additionally, they may also be collected using hypothetical health states described in vignettes using elicitation methods such as the standard gamble (SG). ${ }^{10}$ In a SG study, respondents are typically presented with a choice between two alternatives where in one vignette the health state is certain (eg, no improvement from the current health state described) and in the other there is the option of improved health state (eg, a defined improvement in vision following a specific intervention) but an element of risk (eg, death). The respondent can vary the probability between the improved health state and the risk until the respondent is invariant between the two choices: this represents the respondent's utility value for that health state.

The aim of this study, therefore, was to generate health state utility relating to the use of Holoclar ${ }^{\circledR}$ for the treatment of LSCD using standard gamble, EQ-5D-3L, and EQ-5D vision bolt-on presented via vignettes.

\section{Patients and Methods \\ Sample}

Respondents were recruited via email by a third party (Qualtrics, Provo, USA), which maintains a large series of online panel respondents. The sample was selected to be broadly representative of the UK adult population as this study was intended to inform on the HTA of Holoclar in the UK. Basic socio-demographic details (age, biological sex (male/female/prefer not to say), employment status, and country of residence) were collected from respondents and used to screen for eligibility. Respondents were eligible to participate provided they were a UK resident and aged $\geq 18$ years. However, in order to achieve a UK representative sample, quotas were set based on the socio-demographic variables. Recruitment continued until the quotas were full. The study was conducted via an online platform and participants completing the study received a nominal incentive (redeemable points) reflective of the time required to complete the study. The survey conducted is available in the online Supplemental Material. This was an anonymized survey and no personal medical or personally identifiable data were collected. This study did not need approval from and was not submitted to an ethics review (http://www.hradecisiontools.org.uk). Nevertheless, informed consent was obtained from participants, i.e. the nature and aim of the study was provided to participants prior to participation. Potential participants were also informed that they could leave the survey at any stage. Participants were then asked to provide their consent to participate in the study before the survey commenced. The authors assert that all procedures contributing to this work comply with the ethical standards of the relevant national and institutional committees on human experimentation and with the Helsinki Declaration of 1975 , as revised in 2008 . The data collected were stored on a secure University of York server.

Estimation of the number of participants required was based on a brief pragmatic review of the literature. A total of 29 studies were found where the SG approach had been used to determine health state utilities in ophthalmology/ eye disorders (although not for LSCD). The average sample size of these studies was 212 , although the range was highly varied (44-699). The mean utility and standard deviations were collated from a subset of these studies $(\mathrm{N}=7)$ and entered into a standard sample size formula, 
which resulted in a minimum sample size estimation of $\mathrm{N}=300$. $\mathrm{N}=500$ was used in this study to allow robust estimation of the parameters and to allow a degree of subgroup analysis (eg, gender, age) if required.

\section{EQ-5D-3L}

The EuroQol 5D 3L (EQ-5D-3L) ${ }^{8}$ is a generic utility or preference-based instrument widely used in Health Technology Appraisal (HTA) to determine health state utilities, e.g. for determining cost-effectiveness and costutility estimation. The EQ-5D-3L consists of a descriptive system of five domains: mobility, self-care, usual activities, anxiety/depression, and pain/discomfort, and the EuroQol visual analog scale (EQ VAS). Each domain has three levels (hence $3 \mathrm{~L}$ ), and respondents rate their health state on a scale of $1-3$, where 1 indicates no problems in that domain, 2 indicates some/minor problems in that domain, and 3 indicates extreme problems. The EQ VAS records the respondent's self-rated health on a vertical, visual analog scale where the endpoints are labeled "Best imaginable health state" and "Worst imaginable health state". This information can be used as a quantitative measure of health outcome as judged by the individual respondents. The time frame is the patient self-reported health status on the day of completion. The domain scores or profile scores are converted to health state utilities using country-specific algorithms and the health state utilities reflect societal preferences for the health state in question.

A recent systematic review examining the use of generic and condition-specific measures of HRQoL in NICE decision-making revealed mixed results for the use of EQ-5D in patients with visual disorders, in terms of the measurement properties with performance of the instrument dependent on the nature and etiology of the condition (eg, glaucoma, cataracts, and diabetic foot retinopathy). ${ }^{11}$ Recently a "bolt-on" has been developed for the EQ-5D for use in visual disorders and conditions. ${ }^{11}$ This consists of a single item, "Vision (using glasses or contact lenses as needed)", with three response categories ("no problems/some problems/extreme problems seeing"). However, given its recent development there have only been limited validation studies to date ${ }^{12,13}$ and the value of data derived from this "bolt-on" and its usefulness for HTA has, therefore, yet to be confirmed.

\section{Vignettes}

The vignettes were developed in-house by research physicians involved in the development of Holoclar ${ }^{\circledR}$. Participants were first presented with one of five different vignettes, where they were asked to imagine that they were a patient with moderate-severe LSCD caused by a physical or chemical burn. Each vignette described key symptoms of LSCD, but each differed with regard to the hypothetical symptom profile of the imagined patient. Participants were then asked to complete the EQ-5D-3L with vision bolt-on as if they were a patient with the symptoms described in the vignette.

Participants were then presented with 12 different SG vignettes. For these vignettes, there were three LSCD symptom profiles (pre-treatment health states) that were described. Following each symptom profile, participants were presented with four treatment options and the symptom improvement following treatment, resulting in a total of 12 vignettes. For each treatment option, they were asked to indicate on an analogue slider the percentage risk they would be willing to accept for undergoing treatment that would result in the improvements indicated in the vignette, against the risk of death.

Given the uncertainties regarding the performance of the EQ-5D in visual conditions, and the relative novelty of the EQ-5D vision bolt-on, these approaches were used alongside the $\mathrm{SG}$ in order to derive health state utilities associated with LSCD.

\section{Analysis}

An initial sample of $\mathrm{N}=50$ participants completed the vignettes. These data were checked to confirm the response coding was correct, and the sample corresponded to the pre-specified strata (age and gender in line with the UK population). Profile scores for the EQ-5D-3L were converted to health state utilities using three different UK value sets; i) the Dolan UK tariff for the EQ-5D-3L without the bolt-on using the published algorithm, ${ }^{14}$ ii) the UK value set developed by Longworth et al, for the EQ5D-3L plus vision bolt-on, and, for comparison ${ }^{8}$, and iii) the UK value set developed by Longworth et $\mathrm{al}^{11}$ for the EQ-5D without the bolt-on. The mean and median utility health state values (including 95\% confidence intervals and inter-quartile ranges) were produced across the sample for i) each of the five health state vignettes measured using the EQ-5D-3L, and ii) each of the 12 SG vignettes. The mean and median EQ VAS scores were also generated for each of the health states that were rated using the EQ-5D3L. Mean disutilities were calculated for the symptom profiles of LSCD by creating an average utility for the EQ-5D vignette from the four different methods (EQ VAS and three value sets) and calculating the difference 
between vignettes that differed on limited numbers of attributes. Sensitivity analyses were conducted whereby exclusion rules were developed to exclude participants who gave responses inconsistent with the clinical symptoms, and average utilities were recalculated. The potential underlying factors for these inconsistencies, such as demographic details (age, gender, and occupation) were explored using chi-squared statistics for the EQ-5D and $\mathrm{SG}$ vignettes. To determine whether any inconsistent responses to the EQ-5D vignettes may have affected responses to $\mathrm{SG}$ vignettes, responses from both sets of vignettes were cross-tabulated for those participants with anomalies responses. These were also evaluated using chisquared statistics.

\section{Results}

\section{Sample}

The sample comprised 520 UK residents (267 females; 253 males) aged $\geq 18$ years (7.1\% aged 18-24 years; $17.5 \%$ aged 25-34 years; $17.9 \%$ aged 35-44 years; $19.6 \%$ aged $45-54$ years; $37.9 \%$ aged $\geq 55$ years), who were broadly representative of the UK population. Of these, $49.6 \%$ were managerial/administrative/professional; $36.2 \%$ skilled/semi-skilled/unskilled manual workers; and $14.2 \%$ were state pensioners/unemployed/students; $82.5 \%$ of participants were resident in England; 9.0\% resident in Scotland; $5.8 \%$ resident in Wales; and $2.7 \%$ resident in Northern Ireland.

\section{Health Utilities ED-5D-5L and EQ5D+V}

Table 1 shows the estimates of average utilities obtained by requesting respondents to imagine one of five vignettes in which they were patients with LSCD, which affected their health to different degrees. The full vignettes presented to participants are included in the survey instrument (online Supplemental Material), but briefly they were: i) LSCD in one eye (the other eye is normal), causing poor vision, a disfigured appearance, and pain with photophobia; ii) LSCD in one eye (the other eye is normal), causing poor vision (but no disfigurement or pain); iii) LSCD in one eye (the other eye is normal), causing disfigurement (but normal vision and no pain); iv) LSCD in both eyes, causing poor vision, disfigurement, and pain with photophobia; and v) LSCD in both eyes, causing poor vision. In one eye there is also disfigurement (but there is no disfigurement in the other eye and no pain in either eye).

Vignettes 2 and 3, in which participants imagined they had LSCD only in one eye and with only one type of symptom, had the highest utilities, while vignette 4 , in which participants imagined they had LSCD in both eyes and all three types of symptom, had the lowest. For vignettes where two eyes were affected, average health status ratings were lower and were associated with greater disutility for all four estimates, compared to only having one affected eye. The mean disutility associated with LSCD (causing poor visual acuity with pain and disfigurement) affecting both eyes compared to one eye, calculated by

Table I Average EQ-5D Utilities for Each Scenario

\begin{tabular}{|c|c|c|c|c|}
\hline Scenario & $\begin{array}{l}\text { VAS, Mean } \\
(95 \% \mathrm{CI}) ; \\
\text { Median (IQR) }\end{array}$ & $\begin{array}{l}\text { EQ-5D Utility/Dolan, } \\
\text { Mean (95\% CI); } \\
\text { Median (IQR) }\end{array}$ & $\begin{array}{l}\text { EQ-5D Utilityl } \\
\text { Longworth, Mean (95\% } \\
\text { CI); Median (IQR) }\end{array}$ & $\begin{array}{l}\text { EQ-5D+V Utilityl } \\
\text { Longworth, Mean (95\% } \\
\text { CI); Median (IQR) }\end{array}$ \\
\hline $\begin{array}{l}\text { I }(\mathrm{N}=96) \text { - One eye Poor vision, } \\
\text { disfigurement, pain and } \\
\text { photosensitivity }\end{array}$ & $\begin{array}{l}68.93(65.27- \\
72.58) ; 71.50 \\
(26)\end{array}$ & $\begin{array}{l}0.734(0.676-0.793) \\
0.796(0.38)\end{array}$ & $\begin{array}{l}0.881(0.853-0.909) ; 0.909 \\
(0.18)\end{array}$ & $\begin{array}{l}0.839(0.806-0.872) ; 0.862 \\
(0.25)\end{array}$ \\
\hline $\begin{array}{l}2(\mathrm{~N}=107)-\text { One eye Poor vision, } \\
\text { no disfigurement, pain or } \\
\text { photosensitivity }\end{array}$ & $\begin{array}{l}72.91(69.45- \\
76.36) ; 79.00 \\
(26)\end{array}$ & $\begin{array}{l}0.729(0.675-0.783) \\
0.796(0.38)\end{array}$ & $\begin{array}{l}0.883(0.859-0.907) ; 0.909 \\
(0.14)\end{array}$ & $\begin{array}{l}0.847(0.821-0.874) ; 0.873 \\
(0.16)\end{array}$ \\
\hline $\begin{array}{l}3(\mathrm{~N}=1 \mid 4) \text { - One eye Normal vision, } \\
\text { disfigurement, no pain or } \\
\text { photosensitivity }\end{array}$ & $\begin{array}{l}72.66(68.95- \\
76.37) ; 80.00 \\
(35)\end{array}$ & $\begin{array}{l}0.758(0.707-0.809) \\
0.848(0.38)\end{array}$ & $\begin{array}{l}0.909 \text { (0.889-0.929); } 0.969 \\
(0.14)\end{array}$ & $\begin{array}{l}0.874(0.850-0.898) ; 0.914 \\
(0.17)\end{array}$ \\
\hline $\begin{array}{l}4(\mathrm{~N}=104)-\text { Both eyes Poor vision, } \\
\text { disfigurement, pain and } \\
\text { photosensitivity }\end{array}$ & $\begin{array}{l}64.44(58.75- \\
68.13) ; 70.00 \\
(36)\end{array}$ & $\begin{array}{l}0.578(0.500-0.656) \\
0.690(0.8 I)\end{array}$ & $\begin{array}{l}0.805(0.770-0.84 I) ; 0.838 \\
(0.3 I)\end{array}$ & $\begin{array}{l}0.745(0.702-0.789) ; 0.757 \\
(0.38)\end{array}$ \\
\hline $\begin{array}{l}5(\mathrm{~N}=99) \text { - Both eyes Poor vision, } \\
\text { disfigurement in I eye, no pain or } \\
\text { photosensitivity }\end{array}$ & $\begin{array}{l}65.49(60.86- \\
70.13) ; 70.00 \\
(34)\end{array}$ & $\begin{array}{l}0.637(0.572-0.702) \\
0.691(0.64)\end{array}$ & $\begin{array}{l}0.839(0.81 \mathrm{I}-0.867) ; 0.843 \\
(0.25)\end{array}$ & $\begin{array}{l}0.780(0.743-0.817) ; 0.812 \\
(0.32)\end{array}$ \\
\hline
\end{tabular}


comparing vignettes 1 and 4, was -0.084 across the four EQ-5D-3L estimates (range $=-0.156$ to -0.045 ). The mean disutility associated with unilateral LSCD causing pain and disfigurement in addition to poor visual acuity compared to only poor visual acuity, calculated by comparing vignettes 1 and 2 , was -0.011 (range $=-0.04$ to 0.005 ). The mean disutility associated with bilateral LSCD causing pain and disfigurement in addition to poor visual acuity compared to unilateral LSCD causing only poor visual acuity in one eye, calculated by comparing vignettes 2 and 4 , was -0.104 (range $=-0.151$ to -0.078 ).

Confidence intervals indicated that differences between vignettes 3 (one eye affected, no pain, but disfigurement in one eye) and 5 (both eyes affected, no pain, but disfigurement in one eye) were statistically significant for all three value-set derived utility values, but not for the EQ VASderived utility value. In addition, differences between vignettes 2 (one eye affected, no pain or disfigurement) and 5 (both eyes affected, no pain, but disfigurement in one eye) were statistically significant using the EQ5D $+\mathrm{V}$-derived utility estimate that includes vision problems in the composite.

It should be noted that the Longworth tariff (for the five standard domains, without the vision bolt-on) provided higher estimates of utilities than the Dolan tariff (for the same five domains) overall, and this should be considered when interpreting the results. This is particularly important given an unexpected, and clinically implausible, pattern of results that can be observed when comparing the EQ-5D+V-derived utilities with the Dolan EQ-5D-derived utilities. Utilities in vignettes where participants were asked to imagine that they had poor vision in one or both eyes were higher (ie, closer to perfect health) when derived using the EQ-5D+V tariff, than the Dolan EQ-5D tariff which did not include the bolt-on. Taken on face-value, this suggests that taking poor visual acuity into account when judging an otherwise equal health state, would result in a better HRQoL, a finding that is clinically implausible. In contrast, these discrepancies were not present when comparing the two sets of utilities generated using the Longworth value set, where the average utilities calculated using the vision bolt-on were lower than those which did not account for vision. It should be noted that the EQ-5D vision bolt-on is a relatively newly-developed feature of the EQ-5D and has, as such, not undergone a significant amount of validation. Furthermore, the utility values derived for both the bolt-on and Longworth EQ-5D tariffs were based on relatively small sample sizes $(\mathrm{N}=75)$, which perhaps explains the discrepancy between these and the Dolan tariff.

\section{Standard Gamble}

Table 2 shows the estimates of average utilities obtained using the $12 \mathrm{SG}$ vignettes. The full vignettes presented to participants are included in the survey instrument (online Supplemental Material). Average utility values produced using the $\mathrm{SG}$ vignettes were within quite a narrow range $(\min =0.682, \max =0.765)$. The highest mean utilities were recorded for those treatments where pain and disfigurement improved even if visual acuity did not improve. This was particularly the case for those vignettes where two eyes were affected, although this was also evident where one eye was affected. The next highest mean utilities were recorded for treatments where pain improved and neither disfigurement or visual acuity improved, or where there was only moderate improvement in visual acuity. Again, this was particularly evident for vignettes where two eyes were affected. Finally, where one eye is affected, improving disfigurement but not pain resulted in a greater mean utility, than improving pain but not disfigurement, even when visual acuity improved. Paradoxically, for those vignettes where two eyes were affected the lowest mean utilities were recorded for treatments where there was improvement on all three attributes.

A number of sensitivity analyses were conducted given that some respondents were seemingly responding contrary to the imagined vignettes or in a paradoxical manner. For the EQ-5D-3L vignette 3 there were 57 (50\%) respondents who had indicated problems (ie, scored 2 or 3 ) on the vision bolt-on even though they were asked to imagine they had normal vision. Furthermore, for vignettes 4 and 5 where respondents were asked to imagine they had poor vision 35.6\% (37/104) and 38.4\% (38/99), respectively, indicated they had normal vision. These responses were removed from the results, and the data re-analysed. The results of this analysis are shown in Table 3 . The new values (indicated by the suffix "a") have been included alongside the previous ones. It may be seen from this table that vignette 3 (normal vision) now has the highest level of utility, as would be expected, including on the vision bolton. In contrast to this, those vignettes (4 and 5) with poor vision revealed the lowest level of utility, particularly on the vision bolt-on. No statistically significant results were observed for those participants with anomalous responses to Vignettes 3 , 4, or 5 were observed for gender $\left(\mathrm{X}^{2}{ }_{(1)}\right.$ $=0.042, P=0.84$, Vignette $3 ; X_{(1)}^{2}=0.12, P=0.73$, Vignette 
Table 2 Average Standard Gamble Utilities for Each Scenario

\begin{tabular}{|c|c|c|c|}
\hline Scenario & Pre-Treatment Scenario & Treatment Scenario & $\begin{array}{l}\text { SG Utility, Mean (95\% CI); } \\
\text { Median (IQR) }\end{array}$ \\
\hline 1 & \multirow[t]{4}{*}{$\begin{array}{l}\text { LSCD in one eye, causing poor vision, } \\
\text { disfigurement, and pain with photophobia. }\end{array}$} & $\begin{array}{l}\text { Restores vision to a moderate level and } \\
\text { removes the pain with photophobia. }\end{array}$ & $0.719(0.698-0.740) ; 0.800(0.35)$ \\
\hline 2 & & $\begin{array}{l}\text { Removes disfigurement and the pain with } \\
\text { photophobia. }\end{array}$ & $0.731(0.709-0.753 ; 0.810(0.35)$ \\
\hline 3 & & $\begin{array}{l}\text { Restores vision to normal and removes } \\
\text { disfigurement. }\end{array}$ & $0.709(0.686-0.732) ; 0.800(0.36)$ \\
\hline 4 & & $\begin{array}{l}\text { Restores vision to near normal and } \\
\text { removes the pain with photophobia. }\end{array}$ & $0.682(0.659-0.704) ; 0.760(0.40)$ \\
\hline 5 & \multirow{3}{*}{$\begin{array}{l}\text { LSCD in both eyes, causing vision to be poor in } \\
\text { one eye and moderate in the other, and causing } \\
\text { disfigurement and pain with photophobia in both } \\
\text { eyes. }\end{array}$} & $\begin{array}{l}\text { Removes the pain with photophobia in eye } \\
\text { with moderate vision. }\end{array}$ & $0.745(0.725-0.766) ; 0.810(0.35)$ \\
\hline 6 & & $\begin{array}{l}\text { Removes disfigurement and the pain with } \\
\text { photophobia in the eye with moderate } \\
\text { vision. }\end{array}$ & $0.765(0.745-0.786) ; 0.850(0.34)$ \\
\hline \multirow[t]{2}{*}{7} & & $\begin{array}{l}\text { Restores vision to near normal, and } \\
\text { removes }\end{array}$ & $0.693(0.672-0.715)$ \\
\hline & \multirow[t]{2}{*}{ Only the eye with moderate vision is treated. } & $\begin{array}{l}\text { disfigurement and the pain with } \\
\text { photophobia in the eye with moderate } \\
\text { vision. }\end{array}$ & $0.760(0.40)$ \\
\hline 8 & & $\begin{array}{l}\text { Removes disfigurement and the pain with } \\
\text { photophobia in the eye with moderate vision. }\end{array}$ & $0.750(0.730-0.77 I) ; 0.820(0.35)$ \\
\hline 9 & \multirow{4}{*}{$\begin{array}{l}\text { LSCD in both eyes, causing vision to be poor in } \\
\text { one eye and moderate in the other, and causing } \\
\text { disfigurement and pain with photophobia in both } \\
\text { eyes. Only the eye with poor vision is treated. }\end{array}$} & $\begin{array}{l}\text { Restores vision to a moderate level and } \\
\text { removes the pain with photophobia in the } \\
\text { eye with poor vision. }\end{array}$ & $0.730(0.709-0.75 \mathrm{I}) ; 0.800(0.34)$ \\
\hline 10 & & $\begin{array}{l}\text { Removes disfigurement and the pain with } \\
\text { photophobia in the eye with poor vision. }\end{array}$ & $0.758(0.738-0.779) ; 0.840(0.34)$ \\
\hline 11 & & $\begin{array}{l}\text { Restores vision to near normal and } \\
\text { removes the disfigurement and the pain } \\
\text { with photophobia in the eye with poor } \\
\text { vision. }\end{array}$ & $0.686(0.663-0.709) ; 0.770(0.40)$ \\
\hline 12 & & $\begin{array}{l}\text { Restores vision to near normal and } \\
\text { removes the disfigurement in the eye with } \\
\text { poor vision. }\end{array}$ & $0.720(0.698-0.742) ; 0.800(0.36)$ \\
\hline
\end{tabular}

4; $\mathrm{X}_{(1)}^{2}=0.03$. $P=0.86$, Vignette 5), age $\left(\mathrm{X}_{(5)}^{2}=5.85\right.$, $\left.P=0.32 ; \mathrm{X}_{(5)}^{2}=8.59, P=0.13 ; \mathrm{X}_{(5)}^{2}=6.23, P=0.29\right)$ or occupation $\left(\mathrm{X}_{(2)}^{2}=0.61, P=0.74 ; \quad \mathrm{X}_{(2)}^{2}=2.76, P=0.24 ; \quad \mathrm{X}_{(2)}^{2}\right.$ $=5.37, P=0.07)$.

For the standard gamble vignettes those two vignettes where vision in one or two eyes was restored to near normal in one eye (vignettes 7 and 11) paradoxically scored the lowest in terms of level of utility. For these two vignettes, 42.3\% (220/520) and 37.5\% (195/520), respectively, of respondents had the lowest level of utility compared to vignettes 5-8 and 9-12, respectively. Data were removed from these vignettes and re-analysed to obtain new utility values. These new utilities are shown in Tables 4 and 5. As with the EQ-5D vignettes, the anomalies in these responses were not explained by underlying factors such as age $\left(\mathrm{X}^{2}{ }_{(5)}=2.49, P=0.78 ; \mathrm{X}^{2}{ }_{(5)}=6.55\right.$, $P=0.26)$ or occupation $\left(\mathrm{X}_{(2)}^{2}=1.51, P=0.47 ; \mathrm{X}^{2}{ }_{(2)}=5.57\right.$, $P=0.062$ ) for participants with anomalous responses to 
Table 3 Revised Average EQ-5D Utilities for Each Scenario

\begin{tabular}{|c|c|c|c|c|}
\hline Scenario & $\begin{array}{l}\text { VAS, Mean ( } 95 \% \text { CI); Median } \\
\text { (IQR) }\end{array}$ & $\begin{array}{l}\text { EQ-5D Utility/Dolan Tariff, } \\
\text { Mean ( } 95 \% \mathrm{Cl}) \text {; Median } \\
\text { (IQR) }\end{array}$ & $\begin{array}{l}\text { EQ-5D Utility/Longworth } \\
\text { Tariff, Mean ( } 95 \% \mathrm{CI}) ; \\
\text { Median (IQR) }\end{array}$ & $\begin{array}{l}\text { EQ-5D+V Utility/Longworth } \\
\text { Tariff, Mean }(95 \% \mathrm{CI}) \text {; Median } \\
\text { (IQR) }\end{array}$ \\
\hline I $(\mathrm{N}=96)$ & 68.93 (65.27-72.58); $71.50(26)$ & $0.734(0.676-0.793) ; 0.796(0.38)$ & $0.88 \mathrm{I}$ (0.853-0.909); $0.909(0.18)$ & $0.839(0.806-0.872) ; 0.862(0.25)$ \\
\hline $2(N=107)$ & 72.91 (69.45-76.36); $79.00(26)$ & $0.729(0.675-0.783) ; 0.796(0.38)$ & 0.883 (0.859-0.907); $0.909(0.14)$ & $0.847(0.821-0.874) ; 0.873(0.16)$ \\
\hline $3(N=114)$ & 72.66 (68.95-76.37); $80.00(35)$ & 0.758 (0.707-0.809); $0.848(0.38)$ & 0.909 (0.889-0.929); $0.969(0.14)$ & 0.874 (0.850-0.898); $0.914(0.17)$ \\
\hline 3a $(N=57)$ & 78.26 (73.6I-82.92); $81.00(20)$ & $0.846(0.788-0.903) ; 0.848(0.20)$ & $0.954(0.936-0.972) ; 0.969(0.08)$ & 0.967 (0.950-0.985); $0.997(0.04)$ \\
\hline $4(\mathrm{~N}=104)$ & 64.44 (58.75-68.13); $70.00(36)$ & $0.578(0.500-0.656) ; 0.690(0.8 \mathrm{I})$ & $0.805(0.770-0.84 \mathrm{I}) ; 0.838(0.3 \mathrm{I})$ & 0.745 (0.702-0.789); $0.757(0.38)$ \\
\hline $4 a(N=67)$ & $54.70(48.79-60.16) 51.00(48)$ & $0.414(0.319-0.510) ; 0.516(0.64)$ & $0.726(0.684-0.777) ; 0.755(0.24)$ & $0.635(0.586-0.684) ; 0.660(0.3 \mathrm{I})$ \\
\hline $5(N=99)$ & 65.49 (60.86-70.13); $70.00(34)$ & 0.637 (0.572-0.702); 0.69I (0.64) & 0.839 (0.8II-0.867); $0.843(0.25)$ & $0.780(0.743-0.817) ; 0.812(0.32)$ \\
\hline $5 a(N=61)$ & $56.97(50.94-63.00) ; 57.00(37)$ & $0.509(0.435-0.583) ; 0.516(0.5 \mathrm{I})$ & $0.777(0.746-0.807) ; 0.774(0.17)$ & $0.685(0.646-0.723) ; 0.706(0.24)$ \\
\hline
\end{tabular}

Note: Sensitivity analyses are indicated by the suffix "a" and shown alongside the previous analyses. Sensitivity analyses were conducted given that some respondents were seemingly responding contrary to the imagined scenarios or in a paradoxical manner. Specifically, for the EQ-5D scenario 3 there were 57 (50\%) respondents who had indicated problems (i,e scored 2 or 3 ) on the vision bolt-on, even though they were asked to imagine they had normal vision; for EQ-5D scenarios 4 and 5 where respondents were asked to imagine they had poor vision, $35.6 \%(37 / / 04)$ and $38.4 \%(38 / 99)$, respectively, indicated they had normal vision. These responses were removed from the results and the data re-analyzed $(3 \mathrm{a}, 4 \mathrm{a}, 5 \mathrm{a})$.

Vignettes 7 and 11, respectively, or by gender for Vignette $7\left(\mathrm{X}_{(1)}^{2}=1.56, P=0.21\right)$. However, there was a statistically significant effect by gender for Vignette $11\left(\mathrm{X}_{(1)}^{2}=3.88\right.$, $P=0.049)$, with proportionally more females (57\%) providing lower utility values for this vignette compared to males (43\%) for Vignettes 9, 10, and 12.

There were no statistically significant associations between anomalous responses on the EQ-5D vignettes and SG vignettes, in other words, inconsistent responses on one of these sets was not predictive of anomalous responses on the other (EQ-5D Vignette 3 and $\mathrm{SG}$ Vignette 7, $P=0.75$; EQ-5D Vignette 4 and SG Vignette 7, $P=0.64$, EQ-5D 5 and Vignette 7, $P=0.29$; EQ-5D Vignette 3 and SG Vignette 11, $P=0.49$; EQ-5D Vignette 4 and SG Vignette 11, $P=0.31$; EQ-5D 5 and Vignette 11, $P=0.068$ ).

It may be seen from Table 3 (where anomalous data from vignettes 5 to 8 have been removed) the utility values were higher where respondents were asked to imagine they had two eyes affected compared to one. As with the previous analysis, higher utility values were recorded where both disfigurement and pain were treated. This took primacy over the restoration in vision, particularly where one eye was affected. Where two eyes were affected, marginally higher utilities were recorded for the restoration of normal vision compared to moderate vision (where pain and disfigurement also improved). Furthermore, normal vision was preferred over moderate vision where disfigurement, but not pain was also resolved. One paradoxical result still remained: respondents still scored a relatively low level of utility for the restoration of normal vision and resolution of disfigurement and pain. Once again higher utility values were recorded for those vignettes where two eyes were affected and both disfigurement and pain were removed (Table 4). However, the results in terms of the visual acuity were less clear-cut than for Table 3: although moderate vision was preferred, in general, to poor vision, those vignettes where vision was restored to normal recorded the lowest level of mean utility.

\section{Discussion}

Overall, the utility values generated for LSCD were in line with the level of symptoms described in the vignettes, differing by symptom profile. For both the ED-5D-3L/+V and SG vignettes where one eye was affected, improvements in pain and disfigurement in combination, were associated with a greater mean utility than improvements in visual acuity. Improvements in disfigurement were given a greater mean utility than in pain alone. Similarly, where two eyes were affected greater utility was associated with improvements in pain and disfigurement in tandem in the absence of improvements in visual acuity. In contrast to the vignettes with one affected eye, more utility was associated with improvements in pain in the absence of improvements in disfigurement (or visual acuity).

One caveat on the data generated by this study is that the raw data indicated that some participants failed to accurately imagine the LSCD vignettes prior to completing the EQ-5D-3L. This can be observed in the frequencies of individuals who selected "no problems" in the vision domain of the EQ-5D-3L, in spite of being told they had severe LSCD in both eyes which caused poor vision. Likewise, some individuals expressed visual impairment for vignette 3 , in which they were told that the LSCD did 
Table 4 Revised Average Standard Gamble Utilities for Each Scenario (Anomalous Data from Scenarios 5-8 Removed)

\begin{tabular}{|c|c|c|c|}
\hline Scenario & Pre-Treatment Scenario & Treatment Scenario & $\begin{array}{l}\text { SG Utility, Mean (95\% CI); } \\
\text { Median (IQR) }\end{array}$ \\
\hline 1 & \multirow[t]{4}{*}{$\begin{array}{l}\text { LSCD in one eye, causing poor vision, } \\
\text { disfigurement, and pain with photophobia. }\end{array}$} & $\begin{array}{l}\text { Restores vision to a moderate level and } \\
\text { removes the pain with photophobia. }\end{array}$ & $0.692(0.662-0.722) ; 0.790(0.40)$ \\
\hline 2 & & $\begin{array}{l}\text { Removes disfigurement and the pain with } \\
\text { photophobia. }\end{array}$ & 0.698 (0.667-0.729); $0.790(0.42)$ \\
\hline 3 & & $\begin{array}{l}\text { Restores vision to normal and removes } \\
\text { disfigurement. }\end{array}$ & $0.696(0.665-0.728) ; 0.800(0.42)$ \\
\hline 4 & & $\begin{array}{l}\text { Restores vision to near normal and } \\
\text { removes the pain with photophobia. }\end{array}$ & 0.680 (0.649-0.7II); $0.780(0.4 \mathrm{I})$ \\
\hline 5 & \multirow{2}{*}{$\begin{array}{l}\text { LSCD in both eyes, causing vision to be poor in } \\
\text { one eye and moderate in the other, and causing } \\
\text { disfigurement and pain with photophobia in both } \\
\text { eyes. }\end{array}$} & $\begin{array}{l}\text { Removes the pain with photophobia in } \\
\text { eye with moderate vision. }\end{array}$ & $0.70 \mathrm{I}(0.672-0.73 \mathrm{I}) ; 0.800(0.4 \mathrm{I})$ \\
\hline 6 & & $\begin{array}{l}\text { Removes disfigurement and the pain with } \\
\text { photophobia in the eye with moderate } \\
\text { vision. }\end{array}$ & $0.724(0.695-0.753) ; 0.800(0.4 \mathrm{I})$ \\
\hline 7 & \multirow[t]{2}{*}{ Only the eye with moderate vision is treated. } & $\begin{array}{l}\text { Restores vision to near normal, and } \\
\text { removes disfigurement and the pain with } \\
\text { photophobia in the eye with moderate } \\
\text { vision. }\end{array}$ & $0.725(0.696-0.753) ; 0.800(0.37)$ \\
\hline 8 & & $\begin{array}{l}\text { Removes disfigurement and the pain with } \\
\text { photophobia in the eye with moderate } \\
\text { vision. }\end{array}$ & $0.715(0.685-0.744) ; 0.800(0.4 I)$ \\
\hline 9 & \multirow{4}{*}{$\begin{array}{l}\text { LSCD in both eyes, causing vision to be poor in } \\
\text { one eye and moderate in the other, and causing } \\
\text { disfigurement and pain with photophobia in both } \\
\text { eyes. Only the eye with poor vision is treated. }\end{array}$} & $\begin{array}{l}\text { Restores vision to a moderate level and } \\
\text { removes the pain with photophobia in the } \\
\text { eye with poor vision. }\end{array}$ & $0.717(0.687-0.747) ; 0.800(0.42)$ \\
\hline 10 & & $\begin{array}{l}\text { Removes disfigurement and the pain with } \\
\text { photophobia in the eye with poor vision. }\end{array}$ & $0.733(0.704-0.761) ; 0.810(0.40)$ \\
\hline 11 & & $\begin{array}{l}\text { Restores vision to near normal and } \\
\text { removes the disfigurement and the pain } \\
\text { with photophobia in the eye with poor } \\
\text { vision. }\end{array}$ & 0.699 (0.669-0.730); $0.790(0.4 I)$ \\
\hline 12 & & $\begin{array}{l}\text { Restores vision to near normal and } \\
\text { removes the disfigurement in the eye with } \\
\text { poor vision. }\end{array}$ & 0.709 (0.679-0.739); $0.800(0.42)$ \\
\hline
\end{tabular}

not affect their vision. This may have occurred for a variety of reasons; they may not have been able to recall the details of the imagined health state, or, more likely, some participants may have been answering for their own health state, rather than for the imagined health state. In the sensitivity analysis where these data were removed the highest utility values were shown for normal vision and the lowest for poor vision. This suggests that there were some respondents who had either misunderstood or had difficulties imagining a health state other than their current one.
Similarly, in the SG task, there was a large range in the level of risk that some participants indicated they were willing to accept, with some individuals suggesting that they would willingly accept $100 \%$ risk of death for a treatment which had $0 \%$ chance of improving their health state. While this seems implausible, it is possible that the individuals rating the vignettes considered the pretreatment health state to be worse than death. The sensitivity analysis showed that the removal of pain and disfigurement was the primary factor influencing mean utility 
Table 5 Revised Average Standard Gamble Utilities for Each Scenario (Anomalous Data from Scenarios 9-12 Removed)

\begin{tabular}{|c|c|c|c|}
\hline Scenario & Pre-Treatment Scenario & Treatment Scenario & $\begin{array}{l}\text { SG Utility, Mean (95\% CI); Median } \\
\text { (IQR) }\end{array}$ \\
\hline 1 & \multirow[t]{4}{*}{$\begin{array}{l}\text { LSCD in one eye, causing poor vision, } \\
\text { disfigurement, and pain with photophobia. }\end{array}$} & $\begin{array}{l}\text { Restores vision to a moderate level and } \\
\text { removes the pain with photophobia. }\end{array}$ & $0.7 I 32(0.686-0.74 I) ; 0.800(0.37)$ \\
\hline 2 & & $\begin{array}{l}\text { Removes disfigurement and the pain } \\
\text { with photophobia. }\end{array}$ & 0.721 (0.693-0.750); $0.810(0.42)$ \\
\hline 3 & & $\begin{array}{l}\text { Restores vision to normal and removes } \\
\text { disfigurement. }\end{array}$ & $0.704(0.674-0.734) ; 0.800(0.43)$ \\
\hline 4 & & $\begin{array}{l}\text { Restores vision to near normal and } \\
\text { removes the pain with photophobia. }\end{array}$ & $0.682(0.652-0.7 I 2) ; 0.770(0.4 I)$ \\
\hline 5 & \multirow{2}{*}{$\begin{array}{l}\text { LSCD in both eyes, causing vision to be poor } \\
\text { in one eye and moderate in the other, and } \\
\text { causing disfigurement and pain with } \\
\text { photophobia in both eyes. }\end{array}$} & $\begin{array}{l}\text { Removes the pain with photophobia in } \\
\text { eye with moderate vision. }\end{array}$ & $0.735(0.708-0.762) ; 0.770(0.38)$ \\
\hline 6 & & $\begin{array}{l}\text { Removes disfigurement and the pain } \\
\text { with photophobia in the eye with } \\
\text { moderate vision. }\end{array}$ & $0.749(0.723-0.776) ; 0.840(0.36)$ \\
\hline 7 & \multirow[t]{2}{*}{ Only the eye with moderate vision is treated. } & $\begin{array}{l}\text { Restores vision to near normal, and } \\
\text { removes disfigurement and the pain } \\
\text { with photophobia in the eye with } \\
\text { moderate vision. }\end{array}$ & $0.707(0.680-0.735) ; 0.790(0.4 \mathrm{I})$ \\
\hline 8 & & $\begin{array}{l}\text { Removes disfigurement and the pain } \\
\text { with photophobia in the eye with } \\
\text { moderate vision. }\end{array}$ & $0.737(0.709-0.765) ; 0.810(0.37)$ \\
\hline 9 & \multirow{4}{*}{$\begin{array}{l}\text { LSCD in both eyes, causing vision to be poor } \\
\text { in one eye and moderate in the other, and } \\
\text { causing disfigurement and pain with } \\
\text { photophobia in both eyes. Only the eye with } \\
\text { poor vision is treated. }\end{array}$} & $\begin{array}{l}\text { Restores vision to a moderate level and } \\
\text { removes the pain with photophobia in } \\
\text { the eye with poor vision. }\end{array}$ & $0.718(0.689-0.746) ; 0.800(0.43)$ \\
\hline 10 & & $\begin{array}{l}\text { Removes disfigurement and the pain } \\
\text { with photophobia in the eye with poor } \\
\text { vision. }\end{array}$ & $0.743(0.7 \mid 6-0.77 I) ; 0.830(0.36)$ \\
\hline 11 & & $\begin{array}{l}\text { Restores vision to near normal and } \\
\text { removes the disfigurement and the pain } \\
\text { with photophobia in the eye with poor } \\
\text { vision. }\end{array}$ & $0.723(0.695-0.750) ; 0.800(0.37)$ \\
\hline 12 & & $\begin{array}{l}\text { Restores vision to near normal and } \\
\text { removes the disfigurement in the eye } \\
\text { with poor vision. }\end{array}$ & $0.704(0.674-0.734) ; 0.790(0.43)$ \\
\hline
\end{tabular}

values. Particularly for those vignettes (5-8) where two eyes were affected and vision was moderate, there was a clear indication that the restoration of vision played a part in the utility values (aside from pain and disfigurement), although even here there was the paradoxical result of respondents not rating the restoration of normal vision and the removal of pain and disfigurement as high as improvements in the latter two alone. The picture was less clear for those vignettes involving poor vision in two affected eyes, where, although the removal of pain and disfigurement were once again preferred over the restoration of vision, there was no clear preference between one or two affected eyes. In summary, the highest utility values were shown for those vignettes where disfigurement and pain were removed. The sensitivity analyses showed some evidence that higher utility values were also found where there are two affected eyes and vision is restored to normal (or remains as moderate). 
The sensitivity analysis demonstrated that it is likely that, for some participants, there was some confusion about the nature of the task and the ratings that they were making and that, for others, they were simply completing the task as quickly as possible and not giving the necessary consideration to the task at hand. Analysis suggests approximately $40 \%$ of participants may have been affected in these ways and that these inconsistent responses could not be explained through participants' socio-demographic status. The literature suggests that in other approaches to utility elicitation, such as discrete choice experiments, cognitive burden may play an important role in influencing participant choice. ${ }^{15,16}$ Therefore, the limitations observed are the likely consequence of a combination of several factors, including the complexity of LSCD, its variety of symptom profiles and treatment outcomes, and the on-line methodology used in this study.

A further potential limitation of "vignette" studies is that, when asked to imagine they have an illness, the general public often imagines the impact of the illness at the time immediately following diagnosis, and responds to questions accordingly. ${ }^{17}$ In reality, especially given the time course of LSCD, individuals who have been living with the disease for years may have adjusted to the condition, especially to its impact on visual acuity. As a result of these adjustments, the illness may have a lower impact on the HRQoL of individuals with the illness than is estimated by participants completing vignette studies.

Other limitations with this study include the fact that there is little overlap between the domains on the EQ-5D$3 \mathrm{~L}$ and the vignettes describing $\mathrm{LSCD}$. That said, it may be argued that EQ-5D-3L domains such as Mobility, Selfcare, and Usual Activities could be negatively impacted by LSCD. On the other hand, the EQ-5D-3L does not contain a visual acuity domain, whereas other instruments such as the Health Utilities Index 3 (HUI3) ${ }^{18}$ do contain a vision domain. This argument is, however, partially mitigated by the inclusion of the EQ5D+V. Furthermore, a newer version of the EQ-5D, the EQ-5D-5L was introduced ${ }^{19,20}$ in order to counter criticisms of the lack of sensitivity of the $3 \mathrm{~L}$ version. ${ }^{21}$ It could therefore be argued that either the EQ-5D-5L or the HUI3 may have been more sensitive. Furthermore, the utilities derived from this study were to be included in a health technology assessment (HTA) submission to the National Institute for Health and Care Excellence (NICE); the preferred instrument for HTA submissions to NICE is the EQ-5D-3L. ${ }^{22}$ The choice of instrument was also motivated by these concerns. Nevertheless, it should be borne in mind that the selection of the EQ-5D-3L could have influenced the results.

Given the nature of LSCD, in particular the rarity of the condition, deriving utilities from patients with preference-based instruments such as the EQ-5D-3L and/or vignettes would not lead to robust results due to small sample size. Furthermore, national regulatory agencies such as NICE stipulate a preference for societal valuation of health states. ${ }^{22}$ This, therefore, necessitates the use of elicitation methods, such as the SG. However, there are other vignette methods, for instance the time trade-off $(\mathrm{TTO})^{23}$ and discrete choice experiments ${ }^{24}$ that could have been applied to derive health utilities in this study. There is no consensus on which method is the most appropriate and elicitation processes are known to produce differing health utilities from the same vignettes ${ }^{25}$. In this study the choice was for the SG based on the general agreement ${ }^{23}$ that this method more closely reflects economic utility theory. ${ }^{23}$

In terms of the use of these data for economic valuations, due to the discrepancies between the utilities calculated using the Dolan and Longworth value sets for the five-domain scores (excluding the vision bolt-on), caution should be exercised when deciding on values to use as the base-case in cost-effectiveness analyses. Whilst the Longworth value sets consistently report higher utilities, it is important to note that the differences between health states in Longworth values are lower. For instance, a move from Vignette 5a to Vignette 1 shows a utility change of 0.225 with the Dolan values and 0.102 for Longworth. A move from 4a to 1 shows changes of 0.32 and 0.15 , respectively. Since the results of the economic evaluation are likely to be driven by changes in utility, the Longworth values may be viewed as being more conservative. A post hoc analysis was undertaken of the EQ-5D vignette data (with the anomalous responses removed, $\mathrm{N}=387$ ) using ordinary least squares (OLS) regression (stepwise method). Poor vision (one or both eyes), photosensitivity (one or both eyes), pain and disfigurement (one or both eyes) were coded as dummy variables. These results showed that both poor vision and disfigurement were significant predictors in the models whether the criterion was either based on Dolan or Longworth utilities (none of the other variables were included in the final model). However, the standardized beta coefficients for the Dolan utilities were $-0.371 \quad(t=7.28, \quad P<0.0001)$ and -0.12 $(t=2.36, P=0.019)$ for poor vision and disfigurement, 
respectively; for the Longworth utilities these were -0.49 $(t=10.38, P<0.0001)$ and $-0.13(t=2.82, P=0.005)$, suggesting that, although disfigurement has an equal impact in both tariffs, poor vision has a greater impact in the Longworth utilities. Therefore, although the Longworth values may be considered more conservative, these may be more sensitive to changes affecting vision.

In any case, it would be recommended that different vignette and sensitivity analyses should be conducted to give an impression of how far use of these different inputs would alter the conclusions that could be drawn from costeffectiveness analyses. These results also quantify the uncertainty associated with each utility value.

\section{Conclusion}

This study is the first, to the authors knowledge, ever to report on health state utilities for LSCD. The study showed that improvements in pain and disfigurement appear to be the main factor driving differences in health utilities associated with symptom profiles in LSCD, with improvements in visual acuity having lesser impact. This was particularly the case for bilateral LSCD, but also evident in scenarios describing a single affected eye. As with any elicitation study, it is likely that there was some misunderstanding by some participants throughout the survey but, in the main, the results are in line with expectations.

\section{Acknowledgments}

All study costs were funded by Chiesi Limited, 333 Styal Road, Manchester M22 5LG, UK. The authors are grateful to Dr Catherine Baxter, formerly employed by Chiesi Limited, for the clinical input and advice on developing the vignettes, as well as her contribution to drafting the manuscript, and Dr Chris Bojke, Centre for Health Economics, University of York for advice on the development and interpretation of the results from the standard gamble (SG).

\section{Disclosure}

Dr Adam B. Smith reports Chiesi Ltd funded the study, but was at no time involved in the study design, data analysis and interpretation, nor in the preparation of the manuscript. Dr Jenny Retzler reports grants from Chiesi, during the conduct of the study: The research was carried out by YHEC using funding from Chiesi Pharmaceuticals. Dr Matthew J. Taylor reports his employer (York Health Economics Consortium) received fees for consultancy work in health economics in this therapeutic area, during the conduct of the study; and receives consultancy fees from a range of pharmaceutical and medtech companies, though not in this area, outside the submitted work; The authors reports no other potential conflicts of interest in this work.

\section{References}

1. Baylis O, Figueiredo F, Henein C, Lako M, Ahmad S. 13 Years of cultured limbal epithelial cell therapy: A review of the outcomes. J Cell Biochem. 2011;112(4):993-1002. doi:10.1002/jcb.23028

2. Rama P, Bonini S, Lambiase A, et al. Autologous fibrin-cultured limbal stem cells permanently restore the corneal surface of patients with total limbal stem cell deficiency. Transplantation. 2001;72 (9):1478-1485. doi:10.1097/00007890-200111150-00002

3. Rama P, Matuska S, Paganoni G, et al. Limbal stem-cell therapy and long-term corneal regeneration. $N$ Engl J Med. 2010;363(2):147-155. doi:10.1056/NEJMoa0905955

4. Beare JDL. Eye injuries from assault with chemicals. $\mathrm{Br}$ J Ophthalmol. 1990;74(9):514-518. doi:10.1136/bjo.74.9.514

5. European Medicines Agency. First stem-cell therapy recommended for approval in EU; 19th December 2014 [Internet]. Available from: http://www.ema.europa.eu/ema/index.jsp?curl=pages/news_and events/news/2014/12/news_detail_002239.jsp\&mid= WC0b01ac058004d5c1. accessed August 6, 2018.

6. Milazzo G, De Luca M, Pellegrini G. Holoclar: first of its kind in more ways than one. Cell Gene Ther Insights. 2016;2(2):183-197. doi:10.18609/cgti.2016.023

7. European Medicines Agency 1995-2015 Working together for safe and effective medicines [Internet]. Available from: http://www.ema. europa.eu/ema/index.jsp?curl=pages/about_us/general/general_con tent_000628.jsp\&mid=WC0b01ac058087addd. Accessed 6 August 2018 .

8. Dolan P. Modeling valuations for EurQol health states. Med Care. 1997;35(11):1095-1108. doi:10.1097/00005650-199711000-00002

9. Brazier J, Roberts J, Deverill M. The estimation of a preference-based measure from the SF-36. J Health Econ. 2002;21 (2):271-292. doi:10.1016/S0167-6296(01)00130-8

10. Drummond MF, O'Brien BJ, Stoddart GL, Torrance GW. Methods for the Economic Evaluation of Health Care Programmes. New York: OUP; 2000.

11. Longworth L, Yang Y, Mulhern B, et al. Use of generic and condition-specific measures of health-related quality of life in NICE decision-making: a systematic review, statistical modelling and survey. Health Technol Assess. 2014;18(9):1-224. doi:10.3310/ hta 18090

12. Yang Y, Rowen D, Brazier J, et al. Preference-Based Assessments: an Exploratory Study to Test the Impact on Three 'Bolt-On' Items to the EQ5D. Value Health. 2015;18(1):52-60. doi:10.1016/j.jval.2014.09.004

13. Luo N, Wang X, Ang M, et al. A Vision 'Bolt-On' Item Could Increase the Discriminatory Power of the EQ-5D Index Score. Value Health. 2015;18(8):1037-1042. doi:10.1016/j.jval.2015.08.002

14. Szende A, Oppe M, Devlin N. EQ-5D Value Sets: Inventory, Comparative Review and User Guide. Netherlands: Springer; 2007.

15. Watson V, Becker F, de Bekker-grob E. Discrete Choice Experiment Response Rates: A meta-analysis. Health Econ. 2017;26(6):810-817. doi: $10.1002 /$ hec. 3354

16. Ali S, Ronaldson S. Ordinal preference elicitation methods in health economics and health service research: using discrete choice experiments and ranking methods. Br Med Bull. 2012;103(1):21-44. doi:10.1093/bmb/lds020

17. Arnold D, Girling A, Stevens A, Lilford R. Comparison of direct and indirect methods of estimating health state utilities for resource allocation: review and empirical analysis. BMJ. 2009;339(jul20 3): b2688. doi:10.1136/bmj.b2688 
18. Feeny D, Furlong W, Boyle M, Torrance GW. Multi-attribute health status classification systems: health Utilities Index. Pharmacoeconomics. 1995;7 (6):490-502. doi:10.2165/00019053-199507060-00004

19. Janssen M, Birnie E, Bonsel G. Quantification of the level descriptors for the standard EQ-5D three level system and a five level version according to 2 methods. Qual Life Res. 2008;17(3):463-473. doi:10.1007/s11136-008-9318-5

20. Herdman M, Gudex C, Lloyd A, et al. Development and preliminary testing of the new five-level version of EQ-5D (EQ-5D-5L). Qual Life Res. 2011;20(10):1727-1736. doi:10.1007/s11136-011-9903-x

21. Janssen MF, Bonsel G, Luo N. Is EQ-5D-5L better than EQ-5D-3L? A head-to-head comparison of descriptive systems and value sets from seven countries. Pharmacoeconomics. 2018;36(6):675-697. doi:10.1007/s40273-018-0623-8

22. National Institute for Health and Care Excellence (NICE). Position statement on use of the EQ-5D-5L value set for England. 2019. https:// www.nice.org.uk/about/what-we-do/our-programmes/nice-guidance /technology-appraisal-guidance/eq-5d-5l.accessed 22 July 2020.
23. Torrance GW. Measurement of health state utilities for economic appraisal. J Health Econ. 1986;5(1):1-30. doi:10.1016/0167-6296 (86)90020-2

24. Bansback N, Brazier J, Tsuchiya A, Anis A. Using a discrete choice experiment to estimate health state utility values. $J$ Health Econ. 2012;31(1):306-318. doi:10.1016/j.jhealeco.2011.11.004

25. Martin AJ, Glasziou PP, Simes RJ, Lumley T. A comparison of standard gamble, time trade-off, and adjusted time trade-off scores. Int J Technol Assess Health Care. 2000;16(1):137-147. doi:10.1017/ $\mathrm{S} 0266462300161124$
ClinicoEconomics and Outcomes Research

\section{Publish your work in this journal}

ClinicoEconomics and Outcomes Research is an international, peerreviewed open-access journal focusing on Health Technology Assessment, Pharmacoeconomics and Outcomes Research in the areas of diagnosis, medical devices, and clinical, surgical and pharmacological intervention. The economic impact of health policy and health systems

\section{Dovepress}

organization also constitute important areas of coverage. The manuscript management system is completely online and includes a very quick and fair peer-review system, which is all easy to use. Visit http://www.dovepress.com/testimonials.php to read real quotes from published authors. 